\title{
An objective evaluation of geriatric ward meetings
}

\author{
J. C. GUNN \\ From the Bethlem Royal and Maudsley Hospitals, \\ Camberwell, London
}

Since the second world war the establishment of a therapeutic community within any hospital dealing with psychiatric patients has been regarded as a fundamental objective (W.H.O., 1953). Most hospitals that have attempted such a programme have probably regarded the ward group meeting as an important part of the regime. However, as several authors have pointed out, there have been few attempts to evaluate the efficiency of group psychotherapy in any exact or controlled way (Burchard, Michaels, and Kotkov, 1948; Linden, 1953; Wolff, 1957; Taylor, 1958).

This paper records an attempt to evaluate the effects of a weekly ward meeting on a geriatric unit by using some simple but reliable measures and discusses some of the technical problems relating to the geriatric group situation.

\section{METHODS}

The geriatric unit used for this study is a self-contained block in the Bethlem Royal Hospital, which has an eclectic therapeutic approach and in which all the patients are informal.

In October 1964 there was a break in the customary group meetings and advantage was taken of this in designing the present study. During the year patients received intermittent group psychotherapy by dividing the 12 months into four separate periods: I-13 weeks of the usual unit activities, II-13 weeks of the usual activities plus group meetings, III-14 weeks as in I, and IV-13 weeks as in II.

Each session was held for one hour per week between
1 p.m. and 2 p.m. every Monday, beginning in February 1965. All the patients met each week in the main lounge and arranged themselves in a rough circle, together with the unit doctors available. Outside the main circle and acting only in the capacity of observers, were those nurses not otherwise engaged. The patients were expected to attend the group meeting even if they felt unable to contribute, but no strong pressures were exerted when somebody refused to do so. One of the doctors acted as primary leader of the group and presented the exercise as a forum at which problems could be discussed. The leaders gave most encouragement to discussion of interpersonal conflicts and feelings especially if these had occurred in the ward situation. On the whole, the nurses acted as observers but they were not instructed to be absolutely silent and would occasionally be brought into the discussion by patients, or feel impelled to contribute. No attempt at complex interpretation was made and a non-directive permissive atmosphere was created to encourage free interchange of ideas between the patients themselves.

THE PATIENTS During the year there was a total of 96 admissions, 34 males and 62 females, in the age range of 55-81 years. The characteristics of the ward population with regard to diagnosis was sampled on the first day of every month throughout the year. It can be seen from the Table that the group contained between 12 and 19 patients; it remained constant throughout with a predominance of depressive illnesses $(58 \%)$ and personality disorders $(27 \%)$.

COLLECTION OF DATA The patients' well-being during the period of the trial was measured in terms of physical treatment received, amount of leave taken, and behaviour

TABLE

DIAGNOSIS OF WARD POPULATION BY MONTH

Diagnosis $^{1}$ Nov Dec Jan Feb Mar Apr May June July Aug Sept Oct Monthly \%Monthly

\begin{tabular}{|c|c|c|c|c|c|c|c|c|c|c|c|c|c|c|}
\hline & & & & & & & & & & & & & average & average \\
\hline $\mathbf{S}$ & 1 & 1 & 2 & 2 & 2 & 1 & 0 & 0 & 0 & 1 & 2 & 2 & $1 \cdot 2$ & $7 \cdot 3$ \\
\hline D & 9 & 6 & 8 & 9 & 12 & 6 & 8 & 8 & 12 & 12 & 11 & 13 & $9 \cdot \overline{5}$ & 57.6 \\
\hline 0 & 0 & 0 & 0 & 1 & 1 & 1 & 1 & 1 & 2 & 2 & 0 & 1 & 0.7 & $4 \cdot 8$ \\
\hline $\mathbf{N}$ & 8 & 4 & 5 & 5 & 4 & 5 & 6 & 5 & 4 & 2 & 3 & 1 & $4 \cdot 3$ & $26 \cdot 1$ \\
\hline $\mathbf{P}$ & 1 & 0 & 0 & 0 & 0 & 0 & 1 & 0 & 1 & 1 & 1 & 3 & 0.7 & $4 \cdot 2$ \\
\hline & 19 & 11 & 15 & 17 & 19 & 13 & 16 & 14 & 19 & 18 & 17 & 20 & 16.5 & $100 \cdot 0$ \\
\hline
\end{tabular}

${ }^{1} \mathrm{~S}=$ schizophrenia and schizoaffective psychosis. $\mathrm{D}=$ manic-depressive psychosis and depressive illness. $\mathrm{O}=$ organic brain disease and dementia. $\mathbf{N}=$ psychoneuroses and personality disorders. $\mathbf{P}=$ physical illness other than brain disease. 
recorded in the nurses' notes. To preserve objectivity the latter were unaware of the purpose of the trial or the intention to use their routine records.

(a) $E C T$ The number of treatments given weekly was recorded.

(b) Drugs To quantify the amount of chemotherapy, drugs were converted into units of standard dose, amounts prescribed being recorded from the patient's prescription sheets. The units were as follows : barbiturates $100 \mathrm{mg}$; glutethimide $250 \mathrm{mg}$; chloral hydrate $1.2 \mathrm{~g}$; phenelzine $15 \mathrm{mg}$; tricyclic derivatives $25 \mathrm{mg}$; phenothiazines from $25 \mathrm{mg}$ to $2.5 \mathrm{mg}$ depending on type; diazepam $2 \mathrm{mg}$.

(c) Leave The number of days taken as leave was expressed as a percentage of the total days spent in the unit.

(d) Nurses' opinions At the end of both the day and night shifts, the nurses in charge routinely draw up a report of the ward activities which is furnished to Matron's office. Apart from the factual information, this contains a short account of the preceding 12 hours with reference to all the patients who are sick, those who need special care, and those whose condition warrants special mention.

By inspection of the records it was possible to obtain a measure of the nurses' opinions about patients' behaviour in two aspects (1) behaviour disturbances (2) withdrawal. As a means of measuring these opinions, two lists of words and phrases were drawn up under these two headings from the report material to be rated (see Appendix). Using the word lists a day-by-day count was made of the appropriate items, one point being scored for every phrase and word encountered which was on the list. From the totals obtained under each heading it was possible to calculate the weekly number of points for both disturbance and withdrawal.

To check the reliability of this method of rating, an independent rater was asked to draw up an additional set of figures for both scales on the daytime reports of November 1964 and February 1965 using the same word lists. These months were chosen because they represent both a non-group and a group period. Spearman rank correlation coefficients between the original and the independent sets of data were as follows:

\begin{tabular}{lcc} 
& Behaviour & Withdrawal \\
\hline November 1964 & 0.85 & 0.88 \\
February 1965 & 0.83 & 0.87
\end{tabular}

None of these positive correlations could be attributed to chance $(P<0.001)$. In addition, when each list of ratings was compared with its partner by a Witney Mann $U$ test, there were no significant differences between them. This indicates that the rating method exhibited internal reliability on both scales and that the author's knowledge of the nature and purpose of the experiment during his ratings did not bias the results to a significant extent.

\section{RESULTS}

(A) ECT No significant changes were found.

(B) NIGHT SEDATIVES There was a significant falle⿳亠 in the amount of night sedatives used when the first $D$ group meetings were introduced. However, this result could not be reproduced in the second half $\overline{\bar{\alpha}}$ of the experiment and is not considered further in this paper.

(c) DRUGS (1) Antidepressants A consistent and significant difference was found between the four $\frac{\bar{\sigma}}{\sigma}$ periods. The periods of group psychotherapy (II $\overline{\bar{c}}$ and IV) coincided with a raised consumption of oral $\vec{D}$ antidepressants as compared with the non-group periods (I and III). This can be seen in Fig. 1.1

(2) Major tranquillizers No consistent changes $\vec{\circ}$ were found.

(3) Minor tranquillizers Again, no consistent changes were found.

(D) LEAVE Figure $2^{1}$ indicates that the percentage $\omega$ of leave granted to patients went up during the $\vec{A}$ periods when a ward group was held. This is signd ficant only at the $10 \%$ level, but inspection of the histogram shows that there was a very interestint: and consistent trend for leave to be granted progres sively more freely during the experimental periods and correspondingly less freely during the contrøి periods. Only one month (August) is anomalous to this trend.

(E) NURSES' OPINIONS (1) Behaviour disturbance Using the methods previously described the number of word units indicating behaviour disturbance per patient week was calculated for each week of the study. Male and female figures were considered separately for both day and night reports, but as the complex breakdown added no further information only the total figures are quoted. It is apparent from Fig. $3^{1}$ that the scores of disturbed behaviour are diminished very significantly during the periods of group meetings (II and IV).

(2) Withdrawal Ratings on this scale showed no significant changes.

\section{DISCUSSION}

RESULTS In 1957 Benaim reported his impressions 을 of group psychotherapy on the same geriatric unit, $D$ and concluded that the group therapy, although resembling other group activities in encouraging

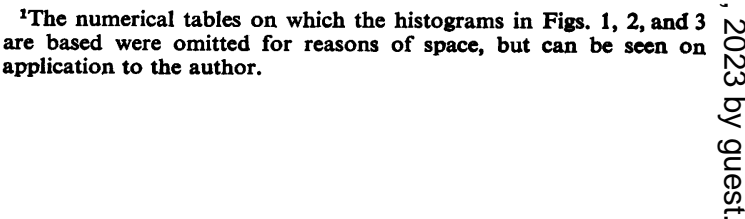




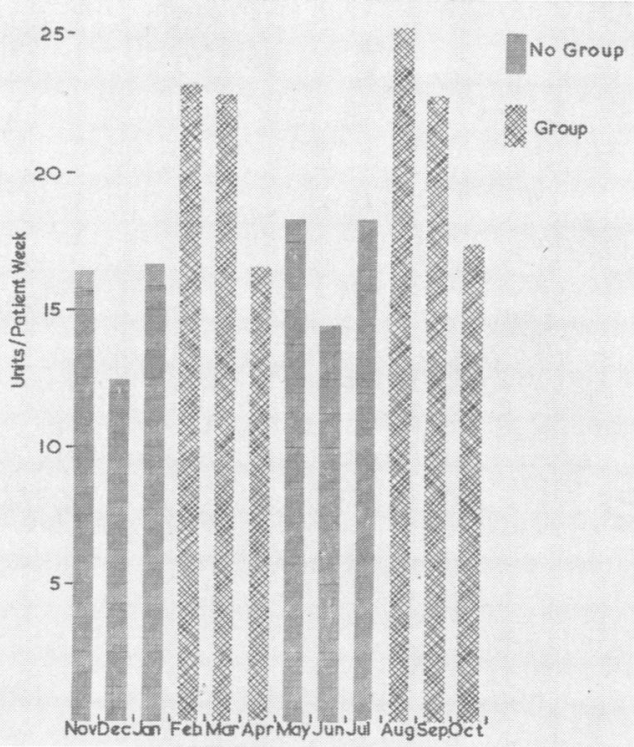

FIG. 1. Antidepressants

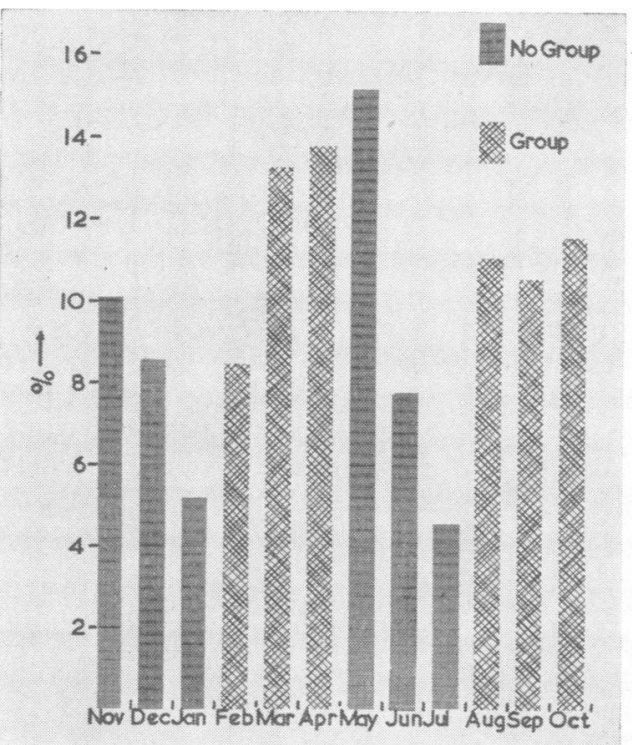

FIG. 2. Patients' leave

socialization, goes further towards the relief of individual patients' anxieties and in improving their adjustment to society. Benaim also thought that the psychiatrist conducting the group learnt more about his patients than he could discover in individual interviews with them.

It is interesting that the results obtained from this experiment go some way towards confirming these impressions, for, in spite of the relative simplicity of the measurements undertaken, three striking and significant changes occurred during the periods of group psychotherapy. There was an increase in antidepressant medication and a decrease in words describing behaviour disturbance appearing in the nurses' notes. In addition, the staff became progressively more liberal in granting leave to patients.

Three possible explanations seem to fit the findings. The first is that the patients remained entirely unchanged by the addition of the therapeutic ward meetings but the staff were influenced by the meetings so that their attitudes towards reporting behaviour disturbance, granting weekend leave, and prescribing antidepressants changed significantly. This seems an unlikely explanation as it ignores the mutual interdependence of all the members of a therapeutic unit, and also the efficacy of antidepressants.

Another hypothesis to be considered is that the group meetings actually made the patients more depressed, and made them act out to a lesser extent-in other words, that there was a symptom shift from behaviour disturbance to depression. Some psychotherapists would argue that this is to be expected and is perhaps a sign of therapeutic benefit. It is difficult to fit the changing pattern of

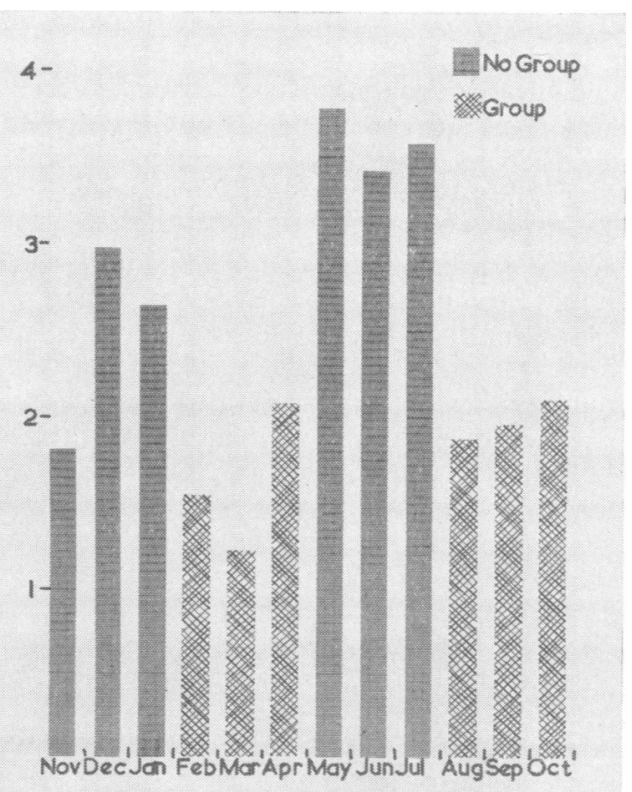

FIG. 3. Patients' behaviour 
leave into this viewpoint, however, as the staff normally grant leave to the less sick patients. The observation could be accommodated only if one assumed that the staff usually measure the degree of illness in a patient by behaviour disturbance rather than depressed affect.

The most satisfactory explanation of the results would seem to be that the group meetings improved the staff's observation of the patients and that this produced improvements in their treatment and hence their mental state. It is possible that such an improvement in observation resulted merely from the increase of time spent by the doctors with their patients. However, the normal practice of this extremely well-staffed unit is to spend two or more hours per week with each patient. A further possibility is that geriatric patients are able to relate to doctors better in the group than in the individual situation or, at least, they are able to express the depressive aspects of their illness more easily. Both Benaim (1957) and Wolff (1957) have commented that for some purposes they prefer to have their geriatric patients in the group situation. Another way of expressing this concept is to assume that geriatric patients find the individual interview very difficult (Wolff, 1957), and that unless there are group meetings with a doctor the depressed old person has to call attention to his misery by acting out. The observations on leave fit this viewpoint well, since an improvement in doctor-patient communication plus an increase in treatment could logically be expected to lead to more home leave being granted.

Whichever explanation of the findings is accepted, the important fact remains that the introduction of therapeutic ward meetings on this geriatric unit did produce changes and these changes were measurable. In view of the simplicity of the technique and the fact that it can be applied completely unobtrusively, it should be possible to compare other ward situations and other techniques in the future.

GROUP TECHNIQUE Several authors have discussed the methods of group psychotherapy best used with geriatric patients. Schwartz and Goodman (1952) treating obese elderly diabetics found a didactic talk on a pertinent topic leading to a discussion to be useful. Wolff (1957) comments that silence and members' anxiety are particularly difficult to handle. His meetings were kept as informal as possible with fruit juice and cigarettes being provided and the therapist aiming to play the role of passive listener. Silver (1950) also favoured a tea-party atmosphere and his sessions included music and singing. Linden (1953) varied his technique but he laid emphasis on the essential quality of light-hearted fun and laughter as opposed to the aura of seriousness in younger patients' groups. He also commented on the ineffectiveness of free-floating discussions and used didactic talks together with a direct question-andanswer technique.

At the end of the experimental year the therapists attending the ward meetings discussed and pooled their views. Several points stand out as unanimous opinions. Firstly, these groups were very different from those conducted with younger adults and the skills learned in the latter form of therapy were inapplicable, possibly even a handicap. The differences noted were that the older folk were remarkably passive, anergic, and uncommunicative. The relatively common physical disability of deafness obstructed verbal interaction considerably. Most of the patients were 'self-centred' and had extreme difficulty in attending to another patient's problems.

From these views and from those quoted from the literature it is clear that the technique which had arbitrarily developed on the ward and which was used for this experiment was not an ideal one. It seems likely that an informal approach would bet preferable and could possibly be expected to produce. more changes in the ward situation, which coul\$ be validated by the methods outlined.

\section{SUMMARY}

A method is described of measuring the effects of therapeutic ward meeting programme on a geriatrie unit in terms of the physical treatment received and the behaviour recorded in routine nursing reports. Consistent and significant changes were found. During the group phases the patients received more antidepressant drugs, were reported as less disturbed and were granted more home leave. At the same time, the experiment high-lighted the deficiencies of the group technique used.

Three possible explanations of the results are briefly discussed: (1) the staff changed as a result of the meetings, (2) a symptom shift occurred from behaviour disturbance to depression, and (3) more and better observation led to improved treatment. It is suggested that similar experimental methods can be used in the future to compare other ward situations and other group techniques.

Dr. F. Post provided a backbone to the study by giving access to his unit, encouragement, and helpful advice at every stage. Dr. L. Hemsi undertook the onerous task of main group leader and was assisted in this by Dr. M. R. Eastwood, Dr. J. Leff, and Dr. C. Ague. Dr. M. Lader provided helpful statistical advice. Charge 
Nurse F. Smith and Deputy Sister P. Walsh cheerfully assisted at every stage, and Dr. B. Blackwell made publication possible by detailed and constructive criticism of the manuscript. Sir Aubrey Lewis gave support and encouragement. To these and many others unmentioned, the author wishes to express his sincere gratitude.

\section{REFERENCES}

Benaim, S. (1957). Group psychotherapy within a geriatric unit: an experiment. Int. J. soc. Psychiat., 3, 123-128.

Burchard, E. M. L., Michaels, J. J., and Kotkov, B. (1948). Criteria for the evaluation of group therapy. Psychsom. Med., 10, 257-274.
Linden, M. E. (1953). Group psychotherapy with institutionalised senile women: study in gerontologic human relations. Int.J. Gr. Psychother., 3, 150-170.

Rechteschaffen, A. (1959). Psychotherapy with geriatric patients: a review of the literature. J. Geront., 14, 73-84.

Schwartz, E. D., and Goodman, J. I. (1952). Group therapy of obesity in elderly diabetics. Geriatrics, 7, 280-283.

Silver, A. (1950). Group psychotherapy with senile psychotic patients. Geriatrics, 5, 147-150.

Taylor, F. K. (1958). A history of group and administrative therapy in Great Britain. Brit. J. med. Psychol, 31, 153-173.

Thomas, G. W. (1943). Group psychotherapy. A review of the recent literature. Psychosom. Med., 5, 166-180.

Wolff, K. (1957). Group psychotherapy with geriatric patients in a mental hospital. J. Amer. Geriat. Soc., 5, 13-19.

World Health Organization. (1953). Third Report of the Expert Committee on Mental Health. Technical Report Survey No. 17. Geneva.

\section{Appendix}

The nurses' notes were rated for their opinions of the patients under two broad headings: (1) behaviour disturbance and (2) withdrawal. One point was assigned to each word or phrase indicating disturbance or with- drawal if it appeared on the lists given below. These lists were devised by a previous inspection of the records to be measured and are obviously unique to this experiment.

(2) WITHDRAWAL

apathetic

(in) bed before 8 p.m.

friendless

keeps to himself

laughs to herself

lonesome

(poorly) occupied

(stays) in own room

pre-occupied

(requires) prompting

(very) quiet

refuses to mix, O.T., to get up, etc

silent

(very) slow

solitary

(not) talking

unoccupied

unsociable

vacant

withdrawn
In the paper by Richard L. Hewer and Norman Robinson, 'Diabetes mellitus in Friedreich's ataxia' (J. Neurol. Neurosurg. Psychiat., 1968, 31, No. 3) the sentence in the summary (page 230) which reads: 'Twelve further cases showed abnormalities of glucose tolerance amounting to diabetes mellitus' should read 'Twelve further cases showed abnormalities of glucose tolerance not amounting to diabetes mellitus'. 